\title{
ANÁLISE DE TESES, DISSERTAÇÕES E ENUNCIAÇÕES DE PROFESSORES SOBRE A ORGANIZAÇÃO CURRICULAR DE ESCOLAS MULTISSERIADAS
}

\author{
Alessandra Corbellini ${ }^{1}$ \\ Ieda Maria Giongo ${ }^{2}$ \\ Marli Teresinha Quartieri ${ }^{3}$
}

\section{RESUMO}

Este estudo é parte integrante da pesquisa denominada Ciências Exatas da Escola Básica ao Ensino Superior, que tem por objetivo evidenciar algumas características presentes nos estudos oriundos de dissertações e teses brasileiras disponibilizadas no portal da CAPES. Estes materiais abordam o tema escolas multisseriadas e são comparados às falas de professores das escolas de dois municípios da Região do Vale do Taquari, representantes desse sistema. O intuito do trabalho é verificar as concepções dos docentes em relação a essa forma de organização, bem como vantagens e desvantagens. Pode-se perceber pela análise efetivada que: primeiro, o interesse dos pesquisadores pela temática vem, ao longo dos anos, aumentando; segundo, os pesquisadores e os professores entrevistados das escolas multisseriadas apresentam convergências e divergências nos processos de ensino e de aprendizagem. Essas escolas situam-se, normalmente, em zonas rurais. Quanto aos conteúdos matemáticos, a maior atenção é dada aos cálculos, deixando a geometria para o final do ano. Muitas vezes, escolas com esse tipo de organização acabam não tendo recursos para materiais didáticos e existe falta de funcionários, deixando para o professor tarefas como merenda e limpeza.

Palavras-chave: Escolas multisseriadas. Concepções de professores. Teses e dissertações. Matemática.

\begin{abstract}
This study is part of the research called Exact Sciences from Elementary School to Higher Education, which aims to highlight some features present in studies from dissertations and Brazilian thesis available in CAPES portal. These materials address the theme multigrade schools and are compared to statements of teachers from schools in two municipalities of the Taquari Valley region, representatives of this system. This paper aims to verify the conception of teachers in relation to this form of organization as well as advantages and disadvantages. It can be seen by effective analysis, firstly, that the interest of researchers in this theme has, over the years, raised; secondly, the researchers and interviewed teachers of multigrade schools have similarities and differences in teaching and learning processes. These schools are usually located in rural areas. As for math contents, most attention is given to the calculations, leaving geometry to the end of the year. Often, schools with this type of organization end up not having resources for teaching materials and there is a lack of staff, leaving to the teachers tasks such as meals and cleaning.
\end{abstract}

Keywords: Multigrade schools. Teachers' conceptions. Thesis and dissertations. Mathematics.

\footnotetext{
${ }^{1}$ Bolsista de Iniciação Científica do CNPq. 〈acorbellini1@ @universo.univates.br>

${ }^{2}$ Doutora em Educação e professora do Centro Universitário Univates. <igiongo@ univates.br>

${ }^{3}$ Doutora em Educação e professora do Centro Universitário Univates. <igiongo@ univates.br>
} 


\section{INTRODUÇÃO}

Este trabalho é parte integrante da pesquisa denominada Ciências Exatas da Escola Básica ao Ensino Superior, desenvolvida no Centro Universitário Univates em Lajeado-RS. O intuito foi problematizar o currículo das disciplinas que compõem o âmbito das Ciências Exatas na Escola Básica e no Ensino Superior. Uma das ações desta pesquisa foi a realização de um estudo sobre escolas multisseriadas, visto que o Brasil ainda apresenta um número significativo dessas Instituições. O objetivo geral foi destacar algumas características presentes nos estudos oriundos de dissertações e teses brasileiras que abordam o tema, em particular em relação à educação matemática no que tange ao ensino da geometria, comparando-as às falas de professores das comunidades de dois municípios gaúchos de origem alemã da região do Vale do Taqueri que ministravam aulas em escolas que apresentavam esse sistema.

Entendemos por escolas multisseriadas uma forma de organização de ensino na qual o professor trabalha na mesma sala de aula com alunos de diferentes idades e níveis educacionais. Para Moura e Santos (2012, p. 6),

o fenômeno das classes multisseriadas ou unidocentes é caracterizada pela junção de alunos de diferentes níveis de aprendizagem (normalmente agrupadas em "séries") em uma mesma classe, geralmente submetida à responsabilidade de um único professor.

A presença de escolas que se organizam dessa forma, segundo os citados autores, foi uma solução adotada para permitir que a população das áreas rurais tivesse acesso à educação, já que a baixa densidade demográfica nessas áreas e o baixo número de alunos estavam inviabilizando a criação de turmas voltadas ao atendimento de séries ou anos específicos.

Segundo Rodrigues (2009, p. 16), "o Brasil possui quase 50\% das escolas de ensino básico concentradas no campo e dessas, 59\% são formadas exclusivamente por escolas multisseriadas". Para o autor, ainda hoje, são essas escolas as responsáveis pela iniciação escolar de muitos brasileiros. E, se não fossem elas, os altos índices de analfabetismo, que sempre marcaram a história da educação nacional, seriam mais alarmantes. A presença delas no território nacional é mais significativa do que muitos imaginam e é uma realidade diferente das urbanas. Por estarem, geralmente, situadas em zonas rurais, pode-se dizer que os alunos têm acesso um tanto limitado aos meios de comunicação e muitos deles, embora jovens ainda, costumam ajudar os pais no período inverso às aulas. Rodrigues (2009, p. 15) também destaca que "quanto às salas multisseriadas, que eu acreditava estarem com os dias contados, estão 
mais presentes na atualidade do que muitos podem imaginar e nem tampouco são uma exclusividade do nosso país”. Entretanto, no Censo de 2013 os dados apontam que o País tem hoje 53.713 escolas com classes multisseriadas do primeiro ao quinto ano do ensino fundamental.

Nesse contexto, este estudo utilizou como material de pesquisa teses e dissertações, disponibilizadas no portal eletrônico da Coordenação de Aperfeiçoamento de Pessoal de Nível Superior (CAPES), que abordam o tema relacionado a escolas multisseriadas. Nestes documentos foram analisados: objetivos, metodologia, referencial teórico e resultados. Além disso, realizaram-se entrevistas com professores das referidas escolas, tendo o intuito de verificar quais conteúdos matemáticos ensinavam, concepções dos docentes em relação a essa forma de organização, bem como vantagens e desvantagens desse sistema escolar.

\section{FUNDAMENTAÇÃO TEÓRICA}

Hage (2006) caracteriza escolas multisseriadas como sendo espaços marcados predominantemente pela heterogeneidade, reunindo grupos com diferenças de série, sexo, idade, interesses, domínio de conhecimentos, níveis de aproveitamento. O autor comenta que essa heterogeneidade ligada ao processo educativo deve ser afirmada na elaboração das políticas e práticas educativas para o meio rural. No entanto, necessita de muitos estudos para que o seu aproveitamento, nessa forma de organização de ensino, não signifique nem continue sendo uma experiência precária de educação. Ozelame (2010) define como escolas multisseriadas turmas nas quais um mesmo professor atende a diferentes séries/anos do Ensino Fundamental. Assim, pode-se ter, em uma mesma sala de aula, turmas de $1^{\mathrm{a}}$ a $5^{\mathrm{a}}$ anos. O autor também comenta em seu trabalho que a própria legislação educacional do Rio Grande do Sul permite esse tipo de organização em escolas onde o número de alunos seja reduzido.

As escolas multisseriadas, segundo Hage (2006), permitem aos sujeitos o acesso à escolarização em sua própria comunidade, o que pode contribuir significativamente para a permanência deles no campo, fortalecendo os laços de pertencimento e de afirmação de sua identidade cultural. Escolas com esse tipo de organização, ao longo do tempo, vêm assumindo um currículo deslocado da cultura das populações do campo, inspirado em compreensões universalizantes. 
envolvem a realidade sócio-econômica-política-ambiental, cultural e educacional do campo, em que se destacam: a degradação das condições de vida, que resulta na intensificação da migração campo-cidade; e o fortalecimento de uma concepção urbano-cêntrica de mundo que generaliza a idéia de que o meio urbano é superior ao campo (HAGE, 2006, p. 4).

O tipo de ensino que as escolas multisseriadas proporcionam vem ao longo da história sendo considerado distante do ideal, resultando no aparecimento de várias abordagens teóricas nos últimos anos e práticas que tentam levantar os problemas desse sistema, tanto do ponto de vista do professor, quanto do aluno, com o propósito de solucionar problemas que os afetam. Rodrigues (2009, p. 18) afirma que sua primeira impressão foi negativa ao se deparar com essa realidade no meio rural, pois "como poderia funcionar uma turma com várias séries e um único professor lecionando ao mesmo tempo?". Além disso, o docente acaba tendo acúmulo de funções. $\mathrm{O}$ autor comenta que parecia impossível associar qualidade a essa realidade e, no início da pesquisa, ao conversar com as pessoas, percebia muita rejeição em relação ao assunto. Entretanto, ao longo de sua investigação, percebeu que as pessoas que possuem um nível de informação mais aprofundado sobre o assunto mostraram-se, se não a favor, pelo menos com uma visão menos pejorativa em relação ao tema.

Existem convergências e divergências quanto aos processos de ensino e de aprendizagem; uns os veem como sinônimo de desvalorização docente, enquanto outros defendem essa organização por alguns motivos importantes. Segundo Rosa (2008, p. 228),

[...] as classes multisseriadas apresentam não só diferenças, mas também semelhanças. Há diferenças quando se consideram as séries, as idades, o sexo, os sonhos, as expectativas, as condições financeiras, socioculturais etc. As semelhanças ocorrem pelo desejo dos alunos de terem acesso a um sistema de educação com boa qualidade de ensino; acesso aos meios de comunicação e conhecimentos; pelos direitos e deveres civis; pela certificação de seu curso.

Moura e Santos (2012, p. 6) comentam que esse sistema tem resistido ao tempo. Em efeito: “tratada nas últimas décadas como uma 'anomalia' do sistema, 'uma praga que deveria ser exterminada' para dar lugar às classes seriadas tal qual o modelo urbano, este modelo de organização escolar/curricular tem resistido". Os autores, entretanto, comentam que escolas de classes multisseriadas assumem uma importância social e política muito significativa nas áreas em que se situam, pois ainda hoje são responsáveis pela iniciação escolar de muitos brasileiros. Ozelame (2010) alude que essas escolas tiveram historicamente um grande valor para os ideais educativos do país, pois contribuíram para a permanência de pessoas na zona rural, evitando a superpopulação das grandes cidades. 
Nessa direção, vimos que historicamente, estas escolas rurais tiveram um grande valor para os ideais educativos deste país. Elas representam, em um determinado período histórico e político, a ferramenta que consolidaria a identidade nacional, além de contribuir para a permanência das pessoas na zona rural, evitando a super população das grandes cidades (OZELAME, 2010 p. 20).

Pesquisas também têm demonstrado que o docente de classes multisseriadas permanece na escola, geralmente, até sua aposentadoria. Isso faz com que, por um lado, exista um maior envolvimento dele na comunidade em que a escola está inserida e, por outro, pouca troca de professores. Em efeito:

Com referência ao professor investigado, este também se mostrou envolvido no exercício da profissão docente com crianças de $1^{\mathrm{a}}$ a $4^{\mathrm{a}}$ série em classes multisseriadas, identificando-se com esse campo de atuação profissional e demonstrando o desejo de ali permanecer até a sua aposentadoria (ARAUJO, 2007, p. 19).

\section{MATERIAIS}

Inicialmente, foram pesquisadas no portal da CAPES teses e dissertações que versassem sobre o tema em estudo, usando-se os descritores escolas multisseriadas, ou escolas em zonas rurais. Foram encontrados catorze trabalhos, nos quais foram analisados os objetivos, a metodologia, o referencial teórico e os resultados. O período pesquisado foi de 2000 a 2010. Os docentes selecionados lecionavam no $4^{\circ}$ e $5^{\circ}$ anos, e a escolha destes esta alicerçada no fato de que, usualmente, nos dois últimos anos dos Anos Iniciais do Ensino Fundamental os conteúdos geométricos são inseridos nas praticas pedagógicas dos professores. $^{2}$

Além das teses e dissertações pesquisadas, foram realizadas entrevistas com um grupo de seis docentes da Educação Básica do Vale do Taquari, Rio Grande do Sul, nas próprias escolas, para que fosse possível compreender o contexto no qual cada uma delas estava inserida. Foram escolhidos, em particular, os professores de geometria. Além disso, houve o intuito de verificar as concepções desses educadores em relação a esta forma de organização.

Os seis professores entrevistados - três de cada município, cinco do sexo feminino e um do masculino - tinham idade entre 25 e 50 anos. $\mathrm{O}$ do sexo masculino atuava 28 anos na

\footnotetext{
${ }^{2}$ Cabe destacar que esta ação da pesquisa Ciências Exatas na Escola Básica ao Ensino Superior está vinculada ao Grupo GIPEMS (Grupo Interinstitucional de Pesquisa em Educação Matemática e Sociedade) por meio da investigação Educação Matemática, ruralidades e formas de vida da colonização alemã do Rio Grande do Sul: um estudo genealógico que conta com o apoio do CNPq.
} 
mesma escola. Quatro das cinco professoras lecionavam, aproximadamente, há 15 anos em escolas multisseriadas, e duas delas exerciam sua profissão a cinco anos. Em relação à escolaridade, observamos que todos possuíam o Curso de Magistério e duas docentes cursavam graduação em Pedagogia. As perguntas foram realizadas com o intuito de entender a forma de organização, rotina, opinião dos docentes que trabalhavam em escolas com este tipo de organização, conceitos matemáticos estudados pelos alunos, dificuldades em relação ao ensino de matemática, em particular, ao de geometria.

As entrevistas foram gravadas e realizadas por duas professoras pesquisadoras e pela bolsista, ocorrendo, em seguida, a sua transcrição e o levantamento dos dados. A partir desses dados, efetivou-se a comparação com o que foi encontrado nas teses e dissertações estudadas.

Como o estudo se restringiu à analise de escolas multisseriadas de dois municípios de origem alemã do Vale do Taquari, os entrevistados se restringiram a seis docentes de pesquisa, o que certamente não permite que tais resultados sejam generalizados para outros contextos.

\section{RESULTADOS}

A análise dos dados oriundos das teses e dissertações e das entrevistas nos permite inferir a existência de quatro unidades, a saber: (a) o interesse dos pesquisadores pela temática vem, ao longo dos anos, aumentando; (b) escolas multisseriadas situavam-se, geralmente, nas zonas rurais de cidades localizadas, em sua maioria, no interior dos Estados; (c) existem pontos opositores e favoráveis quando o assunto se refere a escolas multisseriadas; (d) quanto aos conteúdos matemáticos, os professores comentaram que a maior atenção era dada aos cálculos, deixando a geometria para o final do ano. A seguir, apresentaremos alguns excertos extraídos do material de pesquisa sobre cada uma das unidades acima citadas.

Verificando os trabalhos encontrados na busca efetivada no portal da CAPES, observamos que, no decorrer da última década, o número de teses e dissertações aumentou. Cabe destacar que, no período pesquisado, em 2001 e 2002, encontramos apenas um trabalho em cada ano. De 2005 a 2009, dez trabalhos disponíveis e, em 2010, dois. Destes, apenas um é tese, sendo os outros treze dissertações de mestrado.

A análise dos catorze trabalhos nos permite inferir que as escolas pesquisadas estavam localizadas em zonas rurais e em locais distantes da zona metropolitana dos Estados. Rodrigues (2009, p. 8) comenta que: 
As salas multisseriadas são rotuladas como sendo sinônimo de atraso e de baixa qualidade por se tratar de turmas compostas por várias séries, com um único professor, localizadas, em sua grande maioria, em localidades rurais, com estruturas - física e material - precárias. No entanto, veremos que o ensino nessas turmas pode ser sim, de qualidade, desde que ofereça condições estruturais mínimas para isso.

Em relação aos professores entrevistados, todos ministravam aulas em escolas multisseriadas, localizadas na zona rural dos municípios, ou seja, distantes da sede do município. Cabe destacar ainda que o acesso a essas escolas também era difícil. Pelos depoimentos dos docentes, alguns alunos caminhavam longos trechos para chegar até "um local onde podem pegar o ônibus" (P3) ${ }^{3}$ que os levasse até a escola. Ademais, os municípios pesquisados eram considerados interioranos por estarem localizados em Regiões distantes da Capital do Estado.

Os depoimentos dos entrevistados e os trabalhos estudados mostraram que não há uma posição unânime em relação às escolas multisseriadas. Os pontos positivos destacados em relação a esse sistema foram:

A maior facilidade em lidar com os alunos do campo, que mesmo não tendo acesso às facilidades da região urbana, apresentam grande interesse pela escola e são mais disciplinados do que os alunos da cidade. [...] apesar de enfrentarem dificuldades para o acesso às escolas e para o trabalho pedagógico, principalmente a falta e inadequação de transporte, os professores demonstram satisfação com o trabalho que realizam. (DIAS, 2009, p. 8)

Entende-se que, embora se justifique tal prática como uma economia de tempo, ela pode apresentar pontos positivos e negativos também. Um aspecto positivo é que os alunos poderão rever periodicamente os conteúdos (repetição) e essa prática pode auxiliar na sua apreensão (memorização). Outro aspecto que pode estimular os alunos de séries mais atrasadas a terem acesso a conteúdos mais complexos. Por outro lado, os alunos de séries mais avançadas têm o seu desempenho limitado por tal prática, uma vez que poderiam ter acessado conteúdos em um grau de complexidade maior que o oferecido. (ROCHA 2007 p.156)

Indisciplina é uma palavra que não pertence ao vocabulário dos professores que observei e aparece como o fator que menos incomoda esses professores, de acordo com o questionário aplicado. Os alunos possuem um respeito enorme pelos professores. (RODRIGUES 2009 p.173)

Claro que a quantidade ajuda, mas ano passado eu tive 18 aqui de séries diferentes e 18 lá numa série, só que aqui, mesmo com essa diferença de idade funcionava bem melhor. Rendia bem melhor que com uma turma só. Se tu tem uma turma só, tu vais ter muita diferença entre as crianças, tu vai ter crianças prontas logo e outras não. Aqui por exemplo, quando tiver uma criança pronta, do $4^{\circ}$ ou $5^{\circ}$ ano, ela ajuda a menor. Ela sempre tem uma atividade, ela nunca fica ociosa" (P1)

$\mathrm{Eu}$ defendo a multisseriada. Eu atuei sempre como professor em classes multisseriadas. Eu respeito a opinião daqueles que acham que tem fragilidades, [...]. Claro que isso exige todo um domínio para se trabalhar com três ou quatro séries. Precisa de atividades diferenciadas, mesmo que elas estejam dentro de um determinado foco, tema ou assunto.(P6)

[...] esse ano eu tenho 14 , dos quais 4 no $3^{\circ}$ ano, 6 no $4^{\circ}$ e 4 no $5^{\circ}$ ano. Eles têm uma aprendizagem diferente. Eu vejo numa sala normal às vezes tu vê que um aluno tem um tempo diferente, tu tens que lá dar uma atenção, explicar de um jeito diferente.

\footnotetext{
${ }^{3}$ Indicaremos por P1, P2, P3, ... os professores entrevistados para preservar -lhes o anonimato. Quando os excertos se referirem aos trabalhos examinados serão indicadas as obras dos quais foram extraídos.
} 
De repente, tem uma atividade do $4^{\circ}$ ano que lá no $5^{\circ}$ ano tem que dar uma retomada" (P3).

O ser humano é aquilo que ele traz da família. No interior, as famílias ainda transmitem ética, transmitem respeito, valores morais. E a escola tem toda uma facilidade em trabalhar bem aquele aluno. Coisas que nos grandes centros urbanos já se perdeu. (P2).

Os professores entrevistados que defenderam as multisseriadas alegaram que os alunos são mais interessados pelo que é ensinado. Além disso, para eles, existe a ajuda mútua entre os discentes, onde os colegas auxiliam os de turmas anteriores que apresentam dificuldades. Devido à junção dos diferentes níveis, o conteúdo acaba sendo retomado. A relação que o professor tem com o aluno e família é mais próxima, pois, como geralmente são poucos por docente, este conhece cada um deles. Ademais, os pais ainda estão mais presentes na vida escolar.

Observamos também que os professores acreditavam que o ensino em classes multisseriadas é válido, uma vez que os alunos são mais disciplinados que os "da cidade". Cabe destacar ainda que a instalação da escola no ambiente do discente a torna mais próxima da realidade deste e assim ele se considera sujeito dessa comunidade.

Em relação aos pontos negativos, os docentes comentaram que as dificuldades não estavam no fato de haver turmas com séries/anos misturados, mas sim na falta de recursos básicos, como infraestrutura, materiais didático-pedagógicos escassos, baixa remuneração, sobrecarga de trabalho, dificuldade de atendimento individual aos alunos, apoio pedagógico insuficiente, dentre outros. O deslocamento, tanto para o professor como para os alunos, era muito cansativo e desconfortável, em ônibus em situações precárias e estradas de chão em péssimo estado. Pelas pesquisas, podemos perceber que a realidade encontrada era de escolas precárias, pouco material didático disponível aos professores, além da sala de aula como professores com muitas funções: dar aula, fazer a merenda e a limpeza da escola.

É muito mais complicado de se planejar a aula, pois as aulas podem acabar ficando repetitivas para alguns $(\mathrm{P} 1)$

Ao longo desta tese se demonstrou como as políticas públicas educacionais implantadas pelo governo brasileiro têm sido omissas quando tratam da escolarização dos habitantes do espaço rural e estão silenciadas no que se refere a formação dos professores para atuar em classes multisseriadas nas escolas do campo. (ROCHA, 2007, p.165)

Pouco lembrado nas pesquisas sobre educação, o professor de sala multisseriada acabou por apresentar-se como um malabarista no sentido de desdobrar-se entre as variadas atribuições que lhe foram impingidas e o professor que consegue mediar aprendizagem para até dezoito crianças, simultaneamente. (TOLEDO, 2005, p. 6).

A precariedade na escola ribeirinha multisseriada é visível não apenas na estrutura inadequada dos prédios das escolas, mas na ausência de materiais de incentivo a leitura, áreas de recreação, brinquedos e especialmente carteiras suficientes para todos os alunos, entre outros. Pois, segundo informações da docente, realizada no 
final de 2007, muitos estudantes sentavam ou deitavam no assoalho para escrever. (PINHEIRO, 2009, p. 91)

Muito mais trabalho. Tu tens que planejar pra todos. Como eu disse, no momento que aqui ficar com turma ociosa não funciona. Eles têm que estar sempre ocupados, mas eu já tenho a prática. (P4)

É necessário rever a forma de trabalho proposto pela escola, a qual utiliza técnicas que levam ao fracasso nas séries seguintes (terceira e quarta), quando a divisão passa a ser ensinada. (WALLAUER, 2006, p. 7)

A conceituação da educação para a população do campo, que se fundamenta nas práticas sociais constitutivas dessa população, vem sendo disseminada e respeitada, em decorrência dos movimentos sociais que a reivindicam. Entretanto, a escola do campo ainda é desprestigiada, o currículo é inadequado, seu atendimento é precário e as políticas que visam seu desenvolvimento são desarticuladas da realidade em que estão inseridas, em consequência de uma ideologia educacional que não valoriza o trabalho rural e o mundo rural (TOLEDO, 2005, p. 125).

No caso dos docentes que ministravam aulas em escolas multisseriadas, observamos pelos excertos extraídos dos materiais de pesquisa que estes precisam ter um senso mais acurado para administrar o seu tempo em sala de aula, visto que a turma é heterogênea e isto exige um ritmo diferenciado, mais ativo. Um professor que leciona no sistema seriado possui quatro horas para trabalhar com uma mesma série e o da sala multisseriada precisava dividir esse mesmo tempo com, no mínimo, duas séries.

As entrevistas também tinham como objetivo investigar quais os conteúdos matemáticos que os professores de escolas multisseriadas acabavam privilegiando em detrimento a outros. Foi observado que os docentes entrevistados privilegiavam o cálculo, em particular as quatro operações fundamentais. $\mathrm{O}$ ensino de algum conceito geométrico era deixado para o final do ano e se sobrar tempo.

Esse ano, agora inclusive, talvez, em função dessa pesquisa eu me atinei a ir atrás e
pesquisar mais cedo alguma coisa. Eu gosto muito do tangran, eu trabalhei ano
passado o tangran também numa outra turma que eu tinha, mas acho que ano
passado não fui muito, além disso. Como eu comentava lá outro dia, a geometria
fica lá para o final do ano e se dá tempo, senão deixa pra outra hora. (P2)
A gente sempre pensa ah tem que saber somar, tem que saber dividir, tem que saber
multiplicar, tem que saber diminuir. E isso é o principal, é a base de toda
matemática, e todo resto fica pra trás, todas as outras coisas acabam ficando (P4).

Como pode ser percebido nos dados coletados nas entrevistas, os professores participantes pouco ou nada ensinavam sobre geometria em Matemática, motivo pelo qual lhes foram proporcionados momentos de formação continuada com foco no ensino de geometria para os Anos Iniciais do Ensino Fundamental. Neste curso, foram problematizadas atividades que tinham como tema perímetro e área de figuras planas, utilizando materiais diversificados, como geoplano, folhas quadriculadas, barbante, entre outros. Os docentes foram instigados a resolver as atividades propostas e, logo após, foram propiciados momentos 
de discussão destas para verificar a viabilidade no contexto de cada um dos participantes. Cabe destacar que estes demonstraram empenho e dedicação durante a realização das atividades propostas, evidenciando como estas se tornariam produtivas quando exploradas nas turmas em que atuavam.

\section{CONCLUSÃO}

A Educação Básica tem recebido muitas críticas de vários setores da sociedade. Alguns argumentam a necessidade de um sistema de ensino que atenda a todos com qualidade, outros destacam a importância de reformulação dos currículos e há aqueles que apregoam que ele está desvinculado de conhecimentos e necessidades dos alunos. Não se pode deixar de mencionar as enunciações sobre as metodologias utilizadas nas salas de aula que acabam excluindo aqueles com maiores dificuldades de aprendizagem; desrespeitando as habilidades e conhecimentos prévios dos educandos.

Ao preferir pesquisas acerca de escolas multisseriadas, era intencional o afastamento da idéia de emissão de opinião sobre a organização do referido tipo de sistema de ensino, das escolas que o adotam ou comparar os processos de ensino e aprendizagem relativos à disciplina Matemática com aqueles gestados nas escolas que não adotam o citado sistema. Foi pretendido evidenciar, por um lado, estudos pertinentes à temática que, muitas vezes, não têm obtido visibilidade fora dos ambientes acadêmicos. Nesse sentido, os resultados aqui apresentados permitem inferir que os objetivos iniciais da investigação foram atendidos.

Por outro, interessa também dar visibilidade e problematizar as enunciações de docentes que atuam ou atuavam nesta modalidade de ensino. Tais interesses podem contribuir para o necessário debate acerca de escolas multisseriadas, tendo em vista que, conforme dados do censo escolar de 2011, “45.716, escolas do Brasil ainda possuíam salas multisseriadas, onde são ministradas aulas para alunos de diferentes idades e séries. Destas, 42.711 ficam na zona rural e 3.005 na zona urbana - são 1.040.395 matrículas na zona rural e 91.491 na urbana" (SMOSINSKI, 2013).

Com relação ao âmbito da educação matemática, houve interesse, sobretudo, em evidenciar como o ensino de Geometria tem estado ausente nas escolas de educação básica, cedendo espaço para conteúdos vinculados à aritmética. Tais questões têm servido de motivação para o seguimento da pesquisa e, principalmente, da problematização dos processos de ensino e aprendizagem da Matemática em cursos de formação inicial e 
continuada de docentes. Cabe destacar que devido aos resultados encontrados, a equipe de pesquisadores tem ofertado cursos de formação continuada de Matemática para docentes dos Anos Iniciais do Ensino Fundamental com foco na geometria, em especial, para este grupo de escolas multisseriadas investigadas.

\section{REFERÊNCIAS}

ARAÚJO, J. D. do S.A. Gênero e prática docente no tempo e espaço de classes multisseriadas: encantos e desencantos de professoras e professores d zona rural de Teresina Piauí. Dissertação (Mestrado em Educação). Universidade Federal do Piauí, Teresina - Piauí. 2007.

DIAS, M. A. A educação no campo: as especificidades da docência em duas comunidades rurais. Dissertação (Mestrado em Educação) - Pontifícia Universidade Católica de Minas Gerais, Belo Horizonte. 2009.

HAGE, S. M. A realidade das escolas multisseriadas frente às conquistas na legislação educacional. In: 29a . REUNIÃO ANUAL DA ANPED, 2006, Caxambu. Anais da $29^{a}$. Reunião Anual da ANPEd. Caxambu, 2006. Disponível em http://www.anped.org.br/reunioes/29ra/trabalhos/posteres/GT13-2031--Int.pdf>. Acesso em: 27 jan. 2013.

OZELAME, G. R. Aprendizagem docente: o desenvolvimento profissional de professores de classes rurais multisseriadas. Dissertação (Mestrado em Educação) - Universidade Federal de Santa Maria. Santa Maria. 2010.

PINHEIRO, M. do S. D. Currículo e seus significados para os sujeitos de uma escola ribeirinha, multisseriada no município de Cametá - Pará. Dissertação (Mestrado em Educação) - Universidade Federal do Para. Belém - Pará. 2009.

PORTAL BRASIL. Prazo para curso de formação de professores do campo segue até 19 de setembro. Disponível em: http://www.brasil.gov.br/educacao/2013/09/prazo-para-curso-deformacao-de-professores-do-campo-segue-ate-19-de-setembro. Acesso em: 28 maio 2014.

ROCHA, S. H. X. Construção da ação docente: aprendizagens de professoras leigas em classes multisseriadas na escola do campo. Tese (Doutorado em Educação) - Universidade Federal de São Carlos. São Carlos/ SP. 2007.

ROSA, A. C. S. Classes Multisseriadas: desafios e possibilidades. Educação e Linguagem. Rev. Educação e Linguagem, n. 18, v. 11, p. 222-237, 2008.

RODRIGUES, C. L. Educação no meio rural: um estudo sobre salas multisseriadas. Dissertação (Mestrado em educação) - Universidade Federal de Minas Gerais. Belo Horizonte. 2009. 
SANTOS, F. J. S.; MOURA, T. V. A Pedagogia das classes multisseriadas: Uma perspectiva contra-hegemônica as políticas de regulação do trabalho docente. Rev. Debate em Educação, v. 4, n. 7, p.65-86, 2012.

SMOSINSKI, S. Brasil tem mais de 45 mil escolas multisseriadas: educadores veem vantagens no modelo. In: PORTAL UOL EDUCAÇÃO, 2013. Disponível em $<$ http://educacao.uol.com.br/noticias/2013/01/15/brasil-tem-mais-de-45-mil-escolas-comturmas-multisseriadas-educadores-veem-vantagens-no-modelo.htm>. Acesso em fevereiro de 2014.

TOLEDO, M. C. M. de. O malabarista: um estudo sobre o professor de sala multisseriada por meio do município de Jussara - GO. Dissertação (Mestrado em educação) - Universidade Católica do Goiás. Goiânia, 2005.

WALLAUER, A. Reflexões sobre a construção da operação de divisão em crianças de $1^{a}$ e $2^{a}$ séries de classes multisseriadas. Dissertação (Mestrado em Educação) - Universidade Federal do Rio Grande do Sul. Porto Alegre. 2006. 